\title{
UM CAMINHO PERCORRIDO: DO FRANCÊS GERAL AO FRANCÊS COM OBJETIVOS ESPECÍFICOS
}

\author{
Guiomar Marins Justino de OLIVEIRA ${ }^{1}$
}

\section{Resumo}

O presente artigo tem por objetivo percorrer as metodologias de ensino do francês, língua estrangeira, dos seus primórdios às abordagens atuais, com a finalidade de permitir uma melhor compreensão do longo caminho realizado e traçado pela língua francesa.

Palavras-chave: Ensino de francês; Metodologias; Língua estrangeira

\section{Résumé}

Le présent article a pour but de parcourir les méthodologies de l'enseignement du français, langue étrangère, du début aux approches actuelles, afin de permettre une meilleure compréhension du long chemin réalisé et tracé para la langue française.

Mot-clés: Méthodologies; Enseignement du français; Langue étrangère

\section{Introdução}

Para entendermos determinadas propostas de ensino da língua francesa para finalidades específicas, devemos olhar para o passado e entender o caminho percorrido pelas metodologias de ensino de línguas estrangeiras. E para isso, nós o faremos, no âmbito desse artigo, a partir das leituras feitas das obras de Christian Puren (1988, 2006, 2009), Claude Germain (1993), Jean-Pierre Cuq (2005), Coste (1978) e Christine Tagliante (2006).

Para iniciarmos nossa reflexão, vale lembrar que o ensino do francês como língua estrangeira só se deu oficialmente depois que seu ensino, como língua materna,

\footnotetext{
${ }^{1}$ Professora de francês, formada pela PUC-SP em 1999. Atualmente, desenvolve pesquisas em FLE e FOS e atua como professora autônoma de francês, especializada em FOS. Mestre pela FFLCH-USP (2009).
} 
se consolidou de fato, e mais pontualmente, quando o latim deixou de ser a língua oficial utilizada nas diferentes comunicações; sobretudo a partir de 1539, quando François I promulga o Ordenamento de Villiers-Cotterêts, impondo a prática do francês nos atos jurídicos e administrativos. No entanto, apesar da substituição do latim pelo francês, veremos, na retrospectiva dos períodos metodológicos, que o grego e o latim influenciaram a base do ensino das línguas na Europa.

Eventos de natureza político-econômica sempre trouxeram como consequências mudanças metodológicas no ensino de línguas. Por esse viés, se fizermos um simples paralelo entre as línguas latina e francesa em diferentes momentos da história, veremos que as duas se assemelham muito nos aspectos da inserção da língua na sociedade, no seu ensino e na sua difusão em outras culturas. O latim, língua dos povos dominados pelos romanos, desde o início de nossa era até o século XVII; foi imposto não só como língua de comunicação, mas, já numa outra configuração geopolítica, como a língua oficial durante toda Idade Média, a língua dos assuntos públicos, das relações internacionais e de publicações filosóficas, literárias e científicas, como bem nos mostra o estudo feito por Ana Cristina Bezerril Cardoso, em sua tese de mestrado sobre "Les Serments de Strasbourg": importância histórica e filológica na consolidação do francês (2007). No século IX, segundo essa autora, a língua materna era o proto-francês, originada do latim vulgar e era reservada ao povo. O proto-francês, apesar de ter sido reconhecido como língua oficial local pelos Juramentos de Estrasburgo no século IX, era uma língua que abrigava vários dialetos e foi somente regulamentada no século XVI, em pleno movimento Humanista, com o aparecimento da imprensa. Nesse mesmo período, o latim sofreu sua primeira alteração significativa, perdendo seu estatuto de língua falada e assumindo um novo papel como língua do conhecimento. Na segunda metade do século XVI, a língua sofreu mudanças no seu ensino devido à influência de escritores franceses, como Rabelais, Montaigne, Bellay e Ronsard, que ajudaram a implantar o francês como língua de comunicação usual, tornando o latim apenas uma disciplina escolar. Por volta do século XVII, o francês assumiu seu posto de língua materna oficial, passando a dominar todos os registros públicos e oficiais do país e através do seu ensino, inseriu-se e influenciou as várias áreas de conhecimento em muitos países. Em 1714, por exemplo, o francês passou a ser a língua oficial dos documentos jurídicos internacionais, mantendo-se como língua diplomática até a guerra 
de $1914^{2}$. Na Europa, a língua francesa fazia parte não só da diplomacia, mas fazia parte igualmente da aristocracia, característica que foi também exportada para a América Latina.

Klinnenberg, em seu artigo Les politiques linguistiques: pour qui ? pourquoi? (2000), nos explica que, na Antiguidade, as políticas linguísticas francesas eram pouco explícitas, pois atingiam seus objetivos e sua estabilidade de forma progressiva e interativa. Atualmente, o governo francês, através de ações bem mais explícitas, busca mostrar ao mundo que a língua, apesar do seu papel na comunicação, traz consigo não só uma França, que vive intensos problemas sociais e político-econômicos, mas, sobretudo, uma França tecnológica e científica, com qualidades democráticas, desejosa de ver seu espaço externo expandido ${ }^{3}$.

Podemos perceber que a França, desde a consolidação do francês, busca manter seu estatuto linguístico nacional e global. Daí nosso interesse em iniciar este tema sobre as metodologias de ensino do francês, língua estrangeira, refletindo sobre a língua francesa como um assunto de Estado para a França, pois ela foi e é considerada a partir do seu uso não só pelo cidadão francês, mas pela comunidade internacional. O interessante é que esse cidadão francês de hoje é como a sua língua do século IX, "abrigado por vários dialetos", ele é o resultado de uma imigração muito variada que acontece há décadas no país. A imigração na França "é um fenômeno que tomou formas inelutáveis e sensíveis para a língua" [francesa] (CHEVALIER, apud DEMARTYWARZÉE e ROUSSEAU, 2000:8), por isso, o ensino do francês língua estrangeira dos últimos anos demanda dos professores e pesquisadores uma ação mais consciente no que se refere ao conteúdo linguístico e ideológico a ser ensinado, à forma como isso acontece e ao público a ser formado.

O conhecimento de uma língua estrangeira, nos dias de hoje, possibilita uma melhor integração com a cultura estrangeira correspondente; e a noção de que saber a

\footnotetext{
${ }^{2}$ www.tlfg.ulaval.ca/axl/francophonie/HIST_FR_s6_Grand-Siecle.htm

${ }^{3}$ Como curiosidade, vale mencionar o artigo da Revista da Folha, de 05 de abril de 2009 - "Voilà: um jeito francês de encarar São Paulo" - que começa com os seguintes dizeres: "Dentre os 11 milhões de habitantes da capital [São Paulo], eles são cerca de 6.000 e têm uma missão definida para 2009. No ano da França no Brasil, os franceses radicados na metrópole querem mostrar à terra que os recebeu o lado moderno do seu país de origem, conhecido pela sofisticação, pela veia revolucionária e até pelo mau humor. 'Em 2005, no Ano do Brasil na França, 15 milhões acompanham a programação que por aqui havia mais do que Carnaval e futebol', diz Thierry Valentin, diretor do Centro Brasileiro de Documentação Técnica e Científica. 'Agora, queremos mostrar a cultura contemporânea de lá. Olhar para frente e não para trás.",

${ }^{4}$ Texto original em francês : «(...) l'immigration est un phénomène inéluctable qui prend des formes variées avec des conséquences sensibles pour la langue (...)»- (CHEVALIER, in DEMARTY-WARZÉE e ROUSSEAU, 2000: 8). Nossa tradução.
} 
língua é importante para a integração numa dada cultura não passou despercebida pelo governo francês: em 2007, deputados franceses aprovaram um projeto de lei no âmbito da política imigratória que consistiu na obrigatoriedade da avaliação do conhecimento da língua e dos valores da República ${ }^{5}$. Segundo o Ministro da Imigração francês da época, Brice Hortefeux, a língua é o melhor vetor de integração ${ }^{6}$. Para a França atual, essas medidas lhe permitem uma melhor relação política com os seus candidatos à imigração. Para nós, professores, tais palavras nos fazem refletir sobre a importância de uma formação intercultural, que prepare o indivíduo para um mundo já globalizado, possibilitando-lhe boas oportunidades pessoais e profissionais e, no caso da França, que o habilite a se candidatar para lá viver, visitar, trabalhar e/ou aprender.

Ter a noção dos caminhos percorridos pela língua francesa e pelas suas metodologias de ensino, faz com que percebamos que o importante não é só a difusão da língua e o seu número de falantes, mas a manutenção da eficácia de seu próprio ensino, como bem nos explica Jean Rousseau e Jacqueline Demarty-Warzée (2000) na apresentação do Cahiers du Ciep", quando trataram do tema "Francês do futuro e o futuro do francês". Para esses pesquisadores tratar do futuro da língua francesa significa dar atenção, não só às diferentes demandas de aprendizes, mas, e acima de tudo, à crescente demanda dos professores de francês no tocante aos conteúdos a serem ensinados. Ainda segundo esses autores, há "um sentimento de insegurança" que suscita questões de diferentes naturezas pelos professores, como por exemplo, "a língua coloquial falada atualmente na França é ainda a mesma que conhecemos e trabalhamos com nossos alunos?" Pelo que se vem constatando, o francês falado atualmente é poucas vezes considerado como objeto de ensino em FLE. Logo, qual tipo de língua deveria ser objeto de estudo e de aprendizagem dos aprendizes estrangeiros ${ }^{8}$ ? Em nosso entender, o que garantiu e ainda garante hoje o ensino das "diferentes línguas francesas" é a busca incessante por parte de pesquisadores e professores de francês por abordagens eficazes que mantenham o ensino sempre atual. É nesse contexto que o histórico que segue se insere.

\footnotetext{
${ }^{5}$ Texto original em francês «(...) évaluation de la connaissance de la langue et des valeurs de la République », retirado do artigo: L'évaluation du niveau de français au coeur du texte de loi - LE MONDE, 20.09.07, de Laetitia Van eeckhout. Nossa tradução.

${ }^{6}$ Texto original falado por Brice Hortefeux, ministro da imigração francês: "La langue est le meilleur vecteur d'intégration" (...) LE MONDE, 20.09.07, de Laetitia Van Eeckhout. Nossa tradução.

${ }^{7}$ DEMARTY-WARZÉE, J. e ROUSSEAU, J. Français de l'avenir et avenir du français - Les Cahiers du Ciep. Didier, Paris, 2000.

${ }^{8}$ Ver, a esse respeito, Le Magazine littéraire - 2006: l'année des francophonies - défense et illustration des langues françaises - nº451, de março 2006.
} 


\section{Ensino-aprendizagem do Francês Língua Estrangeira}

Como nos mostram os autores citados na introdução desse artigo, a história da metodologia do francês teve o seu início na Idade Média com a Metodologia Tradicional, usada nos programas educacionais da época e baseada no ensino das línguas gregas e latinas. Tal metodologia, que durou cerca de três séculos, era constituída pelos métodos ${ }^{9}$ gramática-tradução e/ou leitura-tradução e atribuía grande importância ao uso da gramática normativa. A língua era concebida como um conjunto de regras e exceções da gramática e ocupava um lugar de destaque ao lado dos textos literários. Segundo Germain (1993), a metodologia tradicional ou clássica tratava, na verdade, de formar bons tradutores da língua escrita literária, e para isso, privilegiava a leitura de textos literários e a escrita de compositions a partir dos temas trabalhados em aulas, como habilidades a serem desenvolvidas. Via-se também essa metodologia clássica como uma atividade intelectual desenvolvida pela aprendizagem do idioma estrangeiro. Embora a Metodologia Tradicional fosse a pedra angular, a base do ensino das línguas estrangeiras no século XVII, alguns estudiosos faziam uma má avaliação dos resultados obtidos pelos alunos após sete ou mais anos de ensino. Eles questionavam também a capacidade dos aprendizes, suas necessidades, seus interesses e sua dificuldade em se expressar oralmente na língua estrangeira. A metodologia gramática-tradução possuía uma função puramente formativa e normativa voltada para o aspecto estético da língua trabalhada através de atividades abstratas por meio de memorizações e repetições de regras gramaticais e listas de vocabulários, aspectos esses que contribuíram em muito para a mudança definitiva de metodologia de ensino. Assim, a partir do século XIX, os pedagogos enfatizaram suas críticas a esta metodologia, julgando-a fraca e pouco eficaz no que concernia ao ensino e à aprendizagem dos idiomas.

\footnotetext{
${ }^{9}$ Aproveito, neste momento, o estudo feito por Pietraróia em sua obra Percursos de leitura (1997:26), no qual ela menciona as definições terminológicas adotadas por Galisson e Coste (1976). Segundo esses autores, "o problema encontra-se na utilização do termo método, que tem pelo menos duas acepções bastante diferentes: pode significar tanto o conjunto de procedimentos estabelecidos segundo princípios ou hipóteses linguísticas, pedagógicas, psicológicas e visando um determinado objetivo, quanto um manual ou livro pedagógico. Já o emprego mais frequente de metodologia é o de "conjunto de princípios e de hipóteses que subentendem a elaboração de um método". É essa intersecção entre o primeiro sentido de método e o sentido mais comum de metodologia que gera a ambiguidade. Tentaremos evitá-la, atribuindo primazia e preponderância à metodologia e considerando método um seu resultado, ou pelo menos, um conjunto mais fechado de conceitos e princípios precedidos por questionamentos gerais. No entanto, ficam evidentes tanto a dificuldade de tal utilização quanto a facilidade de uma possível sinonímia".
} 
Consequentemente, para um melhor aproveitamento e desempenho do aprendiz de língua estrangeira, algumas famílias optavam pelo método natural, que consistia na imersão total do aprendiz na língua a ser estudada. Essa expressão, utilizada no século XVII, e emprestada do inglês, designou o método utilizado por mães, governantas e preceptores estrangeiros com as crianças e tinha por estudo a aquisição/aprendizado da língua estrangeira através da convivência, mostrando-se muito mais eficaz do que os programas das próprias escolas. Foi, ainda, através do método natural que alguns autores conseguiram fazer suas primeiras reflexões sobre os processos de aprendizado e aquisição de uma língua pelo aprendiz. Os aspectos que ficaram evidentes foram as escutas e as repetições dos modelos orais e a assimilação inconsciente de regras gramaticais implícitas. A ideia base deste método era de aprender a língua pela prática, aplicando-a por simples imitação da linguagem do outro.

Os aspectos evidenciados acima serviram como argumento forte contra o método gramática-tradução; criticado por trabalhar a língua em sua forma escrita, muito ligada à literatura, não dando ao aluno a oportunidade de aprender a língua oral do cotidiano. No que concerne ao aprendizado de um idioma estrangeiro, a necessidade de expressão oral foi sempre imperativa nos diferentes momentos da história de muitos países, por vários motivos, que vão desde a formação intelectual e profissional dos indivíduos às trocas comerciais, no período que vai da Baixa Idade Média (séc. XI) ao século XV. No caso das trocas, o domínio das línguas estrangeiras propiciou aos comerciantes que cruzassem a Europa, conquistando novos mercados e espaços, mostrando o quanto era forte a relação entre o poder econômico de uma nação e sua língua.

O método natural acabou sendo considerado dentro da alternativa criada para substituir a metodologia gramática-tradução no ensino escolar, por volta de 1850 , apareceram os primeiros sinais da metodologia conhecida como direta, consequência de uma pedagogia realista, que foi buscar nos fatos os instrumentos de um ensino mais voltado à prática do cotidiano. É interessante considerar que estas alterações de metodologia não ocorreram de forma fechada e definitiva. Enquanto a metodologia direta (doravante MD) despontava nos grandes centros e principais capitais francesas, o ensino das línguas grega e latina continuava nos programas educacionais, principalmente nas cidades do interior, através da metodologia tradicional ${ }^{10}$.

\footnotetext{
${ }^{10} \mathrm{Na}$ verdade, como veremos, a metodologia tradicional imperou até os anos 60 ou mais, sobretudo nos níveis mais avançados do ensino.
} 
A MD, apesar de ter tido seu início oficial no século XX por meio de instruções apresentadas pelo Ministério da Educação francês para o ensino secundário (1902), conheceu, como vimos acima, seu real início na abordagem natural, baseada na observação da aprendizagem da língua materna pela criança. Podemos encontrar marcas desta proposta em trabalhos feitos por Berlitz, no século XVI, na Inglaterra, e Chompré, no século XVIII, na França. No entanto, quando falamos em Metodologia Direta nos séculos XIX e XX, falamos do que foi desenvolvido na França e na Alemanha como proposta de ensino. Nesse período, essa metodologia inscreveu-se como uma resposta à gramática-tradução, considerada ultrapassada por ser ineficaz e manter-se calcada nas línguas mortas, e caracterizou-se pela recusa da prática da tradução, tendo, por concepção, a utilização da língua para a comunicação, sem desvios e sem intermediários entre a realidade e a língua estrangeira. A MD priorizou os seguintes aspectos no aprendizado de um idioma estrangeiro: o trabalho com o léxico e com a gramática, o primeiro, indo sempre do concreto ao abstrato, e o segundo aspecto, através do trabalho indutivo e implícito, fazendo com que o indivíduo construísse as regras gramaticais partindo de certas estruturas sempre considerando o seu campo lexical. Foram preconizados, a aquisição do oral e o estudo das pronúncias de fonemas, sílabas e palavras, a progressão dos trabalhos, respeitando as capacidades e as necessidades dos estudantes, do conhecido ao desconhecido, e favorecendo uma abordagem mais global do sentido. Essa metodologia possuía um perfil mais ativo, que além do uso do manual, utilizou exercícios de questões-resposta, interações e trocas constantes entre o professor e seus alunos. Para Puren (1988), a MD envolveu vários métodos de trabalho que a estruturaram, e entre eles, os chamados oral e ativo ${ }^{11}$. A respeito do Método Ativo, este buscava corrigir os excessos da própria MD, relançando tanto objetivos culturais e formativos quanto o lugar da competência escrita no aprendizado da língua estrangeira, e seu emprego foi determinante para a constituição da Metodologia Áudio-Oral (MAO), entre os anos de 1925 a 1960, que representou uma adequação da MD ao contexto escolar vigente.

A Metodologia Áudio-Oral começou nos Estados Unidos e foi vista como uma metodologia com características "susceptíveis de trazer uma nova solução aos

\footnotetext{
${ }^{11}$ Christian Puren, em seu livro Histoire des Méthodologies de l'enseignement des Langues (1988), conceitua metodologia e método, diferenciando-os. "Os Métodos (p.17) constituem dados relativamente permanentes porque se situam em nível de objetivos técnicos inerentes a todo ensino de línguas". "Metodologias (p.17) situam-se em um nível superior, pois englobam elementos sujeitos às variações históricas determinantes". Trechos traduzidos por mim. Nossa tradução.
} 
problemas do ensino das línguas [estrangeiras]"12 (1978:13). Segundo os autores estudados, essa metodologia americana, concebida durante a Segunda Guerra Mundial, teve por base de trabalho os conhecimentos técnicos antropológicos de descrição da língua dos linguistas da Universidade de Yale (EUA), entre eles Blommfield, um dos responsáveis por desenvolver um método de língua estrangeira para as forças armadas americanas. Através do The Army Method $^{13}$, os especialistas americanos propuseram formar rapidamente um grande número de militares para compreender e falar as diferentes línguas dos campos de batalha da Segunda Guerra. O sucesso deste método acelerou o processo de modernização do ensino de línguas estrangeiras, pois propunha diálogos da vida cotidiana que eram memorizados antes da compreensão do funcionamento gramatical das frases. A partir desta experiência com os soldados, a MAO promoveu o encontro de duas vertentes: a linguística, através do estruturalismo, e a psicologia, através do comportamento. A partir de modelos orais (patterns) trabalhados com os soldados, as estruturas de língua eram reforçadas por meio de exercícios estruturais. A memorização e a imitação promoviam a aquisição de uma gramática indutiva implícita e a aprendizagem privilegiou a forma em detrimento do sentido. A MAO, baseada em teorias linguísticas e hipóteses sobre a aprendizagem, teve um papel importante na aquisição das línguas. Para Leon Jakobovits (apud COSTE,1972), essa metodologia trouxe uma nova visão sobre o ensino-aprendizagem de uma língua estrangeira, pois, para ele, ela acontecia por etapas, fazendo com que as diferentes competências linguísticas fossem trabalhadas e bem mais percebidas pelos professores. $^{14}$

Em 1957, com o lançamento do primeiro Spoutnik, o governo americano decidiu investir no ensino de línguas estrangeiras com o intuito de inserir o povo americano na cultura de outras nações. A experiência com o exército americano foi levada em consideração naquele momento, visto que o seu sucesso ia ao encontro da intenção e necessidade do governo daquela época, resultando na adoção oficial da Metodologia Áudio-Oral nas escolas. Na França, a MAO trazia com ela uma nova concepção de

\footnotetext{
12 Texto original em francês: «(...) susceptibles d'apporter une solution nouvelle aux problèmes de l'enseignement des langues(...) » (COSTE, D. in BOUACHA, 1978 :13). Nossa tradução.

${ }^{13}$ The Army Method - O Método das Forças Armadas. Expressão referente ao método de ensino de línguas criado para atender a demanda do exército americano no período da Segunda Grande Guerra.

${ }^{14}$ Poucos mencionam a questão da motivação nesse ensino: os soldados aprendiam alemão, italiano ou japonês para atuarem como espiões nos campos inimigos e falar bem a língua estrangeira desses campos era condição de vida ou morte. A nosso ver, esse pode ser considerado um dos primeiros ensinos com objetivos específicos... bem específicos na medida, como veremos mais adiante, em que reuniu demanda, motivação e ação.
} 
aprendizagem da língua, tendo, como objetivo, comunicar-se em língua estrangeira. Apesar de visar o desenvolvimento das quatro competências linguísticas, essa metodologia, no seu início, focalizava a compreensão e expressão orais e trazia um aspecto interessante: o léxico ficava em segundo plano em relação às estruturas sintáxicas. Segundo os estudos feitos por Germain (1993), na concepção de aprendizagem dessa metodologia, a língua devia ser adquirida através de hábitos propostos por meio do automatismo sintático e da repetição, conforme preconizavam as teorias behavioristas e skinneriana.

A MAO funcionou bem com os níveis iniciantes, entretanto, com os níveis mais avançados, tornou-se repetitiva e ineficaz, o que gerou seu enfraquecimento, motivado, sobretudo, por dois fatores. O primeiro foi a questão da transferência. O aprendiz não usava de forma espontânea o que tinha aprendido em aula. A memorização e a imitação promoveram a aquisição de um conteúdo fechado que privilegiava muito mais a forma em detrimento do sentido. O segundo fator está ligado à questão da própria aquisição do idioma, considerado algo externo ao indivíduo e totalmente ensinado. Noam Chomsky, através de sua gramática-gerativa-transformacional, posicionou-se contra a teoria de Skinner (estímulo/resposta) dizendo que ele trabalhava a língua de forma superficial. Para o linguista americano, em crítica feita à Skinner na A Review of B.F. Skinner's Verbal Behavior, em 1959, "a aquisição de uma língua, tanto materna quanto segunda ou estrangeira, revelava processos inatos e universais ${ }^{15}$ " $(1993: 147)$.

Nesse mesmo período pós-guerra, a França, com necessidades opostas às do governo americano, precisava manter sua língua difundida e, para isso, tomou algumas medidas. Uma comissão, criada pelo Ministério da Educação Nacional francês, foi incumbida de pôr em prática um "francês elementar" (GERMAIN, 1993), baseado num léxico essencial que facilitasse o aprendizado da língua. $\mathrm{O}$ objetivo do governo francês dessa época era integrar os imigrantes à sua cultura, implantar o ensino da língua francesa no exterior e lutar contra a expansão da língua inglesa.

Petar Guberina, pesquisador da Universidade do Zagreb (Croácia), formulou a base de uma proposta para o governo francês dando assim origem à Metodologia Estruturo-Global Áudio-Visual em 1950. Juntamente com Paul Rivenc, da Escola Normal Superior de Saint-Cloud (França) e Raymond Renard, da Universidade de Mons (Bélgica), ele estabeleceu a aplicação pedagógica de sua metodologia. Para Guberina, “a

\footnotetext{
${ }^{15}$ Texto original em francês : «(...) l'acquisition d'une langue, tant maternelle qui seconde ou étrangère, revèle de processus innés et universels (...) » (GERMAIN, 1993 :147). Nossa tradução.
} 
língua é um conjunto acústico-visual, por isso, a importância da escuta (áudio) e da visão (visual) nesse sistema metodológico ${ }^{16 ", ~(2005: 262) . ~ A ~ t e o r i a ~ v e r b a l ~ d a ~ p e r c e p c ̧ a ̃ o ~}$ do pesquisador croata propunha um método de correção fonética, evidenciando o ritmo e a entonação da língua estrangeira.

No final dos anos 50, o Centro de Pesquisa e de Estudo para a Difusão da Língua Francesa (Crédif) e o Ofício para o Ensino da Língua e de Civilização Francesa no exterior (BELC) desenvolveram vários trabalhos sobre a didática proposta pela Metodologia SGAV e elaboraram o primeiro método em 1962. Com o método Voix et Images de France (VIF), os pesquisadores influenciaram e motivaram o mesmo gênero de produção em outras línguas.

A Metodologia SGAV consistia no trabalho com diálogos, nos quais era usada a língua do cotidiano em situações de comunicação, também usuais, concretizadas pelo uso de imagens que ilustravam o contexto dos diálogos estudados. Segundo Cuq e Gruca (2005), a noção estruturo - global áudio-visual mostrou que todas as estruturas da língua exercidas por meios verbais, aconteciam por meios não-verbais e que a língua era considerada também a partir de seu gestual: fatores esses que interferiam na comunicação oral. Como bem nos explica ainda os autores, uma aula $S G A V$ acontecia em várias fases. A primeira era de apresentação do diálogo, objetivando a compreensão global da situação. A fase seguinte consistia na explicação da situação e dos elementos desconhecidos a partir da retomada do diálogo e das imagens na sequência. A terceira era a fase da repetição e era reservada para a correção fonética e memorização das estruturas do diálogo. Passava-se, então, para exploração dos elementos desconhecidos, para finalizar com a fase da transformação do conteúdo adquirido pelo aprendiz através de uma representação/dramatização. Nesse período, a metodologia $S G A V$ dedicou-se a integrar no seu ensino a comunicação através da expressão oral e não mais na língua como objeto. Para isso, baseou-se em teorias precisas e no sistema verbo-tonal (audição e fala) posto em prática por Guberina (1950), que consistiu na aquisição da fonética da língua estudada através da maturidade do indivíduo dentro do seu processo de aprendizagem. Ou seja, os procedimentos adotados no $S G A V$, no que dizia respeito ao sistema fonológico da língua estrangeira, eram trabalhados por meio de procedimentos que permitiam a auto correção / reprodução do indivíduo a partir de sua própria

\footnotetext{
${ }^{16}$ Texto original em francês : «(...) la langue est un ensemble acoustico-visuel ; d'où l'importance de l'oreille (audio) et de la vue (visuel) dans ce système méthodologique. »(CUQ\&GRUCA, 2005 :262). Nossa tradução.
} 
percepção auditiva. A Metodologia Áudio-Visual, que teve seu início nos anos 50, conheceu três períodos de evolução. O primeiro, por volta dos anos 60, foi considerado o período de filiação à $S G A V$ por Guberina e seus colaboradores. A segunda, já no período dos anos 70, consolidou-se em torno do manual Voix et Images de France $V I F$, elaborado pelo Crédif e pelo BELC. As aulas ganharam uma nova abordagem devido ao empobrecimento dos diálogos com personagens sem perfil psicológico. De Vive Voix (Didier, 1972) e C'est le Printemps (CLE International, 1975/78) são dois dos manuais que marcaram esse período e anunciaram a chegada da Abordagem Comunicativa, a terceira e última fase do período $S G A V$, que representou a nova orientação da metodologia audiovisual, voltada também para um novo público, com interesses específicos e científicos. Essa fase representou o início da integração de novos procedimentos didáticos "nocional-funcionais e comunicativos".

Os problemas econômicos da década de 70 levaram o governo francês a reagir político-economicamente e a lançar um novo investimento linguístico. A Abordagem Comunicativa "nasceu de um cruzamento de fatores políticos e de novas teorias de referência ${ }^{17 ", ~(C U Q ~ e ~ G R U C C A, ~ 2006: 264) . ~}$

A preocupação em aproximar o ensino do francês de situações comunicativas gerou muitas mudanças na prática pedagógica e no material didático produzido. $\mathrm{O}$ uso de documentos autênticos no ensino do francês fez com que o estruturalismo adotado até então fosse substituído definitivamente por uma opção pedagógica mais comunicativa. Sendo assim, a Abordagem Comunicativa, que priorizou a comunicação, teve seu início nos anos 80 e manteve-se até a publicação do Quadro Europeu Comum de Referência para as Línguas em 2001. Essa abordagem, apesar de inscrita dentro da proposta da Metodologia Áudio-visual, realizou grandes mudanças nas práticas de ensino. Como o principal objetivo para essa abordagem era a comunicação, os seus adeptos consideraram que, para que ela fosse atingida de forma eficaz, era preciso adaptar os conteúdos linguísticos às situações comunicativas. Em outras palavras, era preciso adaptar e inserir o estatuto do interlocutor (idade, posição social, onde mora, etc.), a sua intenção de comunicação (solicitar e/ou dar uma informação, dar ordens, identificar alguém ou um objeto, etc.) e a sua situação de comunicação. Isso valeu tanto para a expressão escrita quanto para a oral. A competência a ser priorizada em curso dependia muito da necessidade do aluno e da proposta do conteúdo trabalhado. Logo,

17 Texto original em francês : «(...) l'approche communicative est née d'un croisement de facteurs politiques et de nouvelles théories de référence. » (apud CUQ \& GRUCA, 2005 :264). Nossa tradução. 
aprender uma língua na perspectiva comunicativa consistiu no aprendizado de regras que permitissem muito mais elaborar enunciados do que repetir os já conhecidos pelo aprendiz. O professor, nessa perspectiva de trabalho e dentro de uma concepção cognitiva, procurou favorecer as interações entre os aprendizes, propondo-lhes situações de comunicação estimulantes.

Dessa iniciativa surgiu o Niveau-Seuil (Hatier - Conselho da Europa, 1976), na França, escrito por Daniel Coste e Janine Courtillon. Esta obra levantou o maior número possível de enunciados em situação de comunicação para os seus respectivos atos de fala, o que levou os especialistas a determinar os componentes essenciais para o ato comunicativo e estabelecer a noção da necessidade do aprendiz nos programas de Abordagem Comunicativa. Cuq e Gruca (2005:265), a partir dos estudos realizados por Canale, Swain e Moirand, distinguiram quatro componentes dentro dessa abordagem. $\mathrm{O}$ primeiro é "o componente linguístico, ou seja, o conhecimento das regras e das estruturas gramaticais, fonológicas, lexicais, de uma dada língua. Este componente constitui uma condição necessária, mas não suficiente para que o indivíduo possa comunicar-se em língua estrangeira." O segundo, “o componente sociolinguístico que leva ao conhecimento das regras socioculturais de emprego da língua e que impõem o saber utilizar as formas linguísticas apropriadas em função da situação e da intenção de comunicação." O terceiro, "o componente discursivo, que garante a coesão e a coerência dos diferentes tipos de discurso em função dos parâmetros da situação de comunicação na qual ele se insere." O último componente, "a competência estratégica constituída pela capacidade de utilizar estratégias verbais e não verbais para compensar as faltas e os "erros" da comunicação. Esses fenômenos de compensação podem ser exercidos ou na competência linguística, ou na competência sociolinguística" 18 (CUQ \& GRUCA, 2005:265, 266). Algumas questões resultaram do estabelecimento dos quatro componentes e uma delas foi o aprender a adaptar-se ao saber comunicar-se,

\footnotetext{
${ }^{18}$ Texto original em francês : « (...) - une composante linguistique, c'est-à-dire la connaissance des règles et des structures grammaticales, phonologiques, du vocabulaire, etc. Cette composante consiste une condition nécessaire, mais non suffisante pour pouvoir communiquer en langue étrangère; - une composante sociolinguistique qui renvoie à la connaissance des règles socioculturelles d'emploi de la langue et qui impose de savoir utiliser les formes linguistique appropriées en fonction de la situation et de l'intention de communication ; - une composante discursive qui assure la cohésion et la cohérence des différents types de discours en fonction des paramètres de la situation de communication dans laquelle ils s'insèrent; - et, enfin, une composante stratégique constituée par la capacité d'utiliser des stratégies verbales et non verbales pour compenser les défaillances ou les «ratés» de la communication. Ces phénomènes de compensation peuvent s'exercer soit sur la compétence linguistique, soit sur la compétence sociolinguistique. » (CUQ \&GRUCA, 2005 : 266) - Nossa tradução - as citações traduzidas foram inseridas no corpo do texto em três momentos no mesmo parágrafo.
} 
respeitando as regras de emprego da língua e valorizando sua intenção numa dada situação comunicativa. Outra questão de extrema importância para o ensino da língua francesa foi a noção de necessidade, que permitiu distinguir o ensino do francês generalista do francês especializado de forma mais objetiva, através do levantamento das necessidades linguageiras, que vão, por sua vez, orientar a progressão gramatical e lexical. O interessante a ser considerado é não somente a distinção dos tipos de ensino em língua francesa (o ensino geral e o de especialidade ou específico), mas os ajustes feitos nas concepções de professor, de aprendiz, de produção de material pedagógico, de ensino e aprendizagem e as relações estabelecidas entre eles. Esses ajustes permitiram uma melhor "modalização" do ensino do francês, assentando-o e instituindo-o de forma a responder aos diferentes níveis de necessidades (as necessidades do professor, as do aluno, as da instituição, etc.), o que foi chamado de Abordagem Funcional/Nocional. Para Tagliante (2006), essa abordagem foi uma variante dentro da perspectiva comunicativa e concentrou-se na busca das necessidades linguageiras. Em seu livro La classe de Langue (2006), ela cita o manual Archipel como exemplo de um material produzido inteiramente para responder às necessidades do aprendiz, considerando que a noção do ensino voltado para uma necessidade específica do aluno ainda não estava em questão; e, quando o analisamos, fica realmente evidente seu caráter inovador para aquele momento.

Ainda no percurso das metodologias de ensino do Francês Língua Estrangeira, vemos que a Abordagem Comunicativa manteve-se aproximadamente, durante vinte anos, abrindo-se a outras propostas, adequando-se e/ou buscando adequar-se aos momentos da sociedade, da política e mesmo da língua francesa. A herança deixada pela Abordagem Comunicativa, de ensinar o aluno a ser autônomo e envolvido com o seu processo de ensino da língua estrangeira, trouxe uma nova perspectiva para o ensino do francês. As competências mais passivas - compreensão oral e escrita, bem como as de produção oral e escrita assumiram um novo papel, fazendo com que o aprendiz se inserisse em situações de interações e mediações, através de sua própria ação, o que gerou um novo movimento metodológico nos anos 90.

A Abordagem Acional (AA) apareceu oficialmente com a publicação, em 2001, do Quadro Europeu comum de referência e teve por objetivo mudar a concepção do aluno no âmbito do processo de ensino-aprendizagem da língua estrangeira. O aprendiz passa a ser considerado um "ator social", com competências comunicativas e estratégicas, para realizar as ações que lhe interessam ou que lhe são solicitadas em 
língua estrangeira. Enquanto a Abordagem Comunicativa dedicou-se à comunicação entre o seu aprendiz e outras pessoas em determinadas situações, a Abordagem Acional dedicou-se e dedica-se à ação a ser realizada pelo aprendiz como ponto de partida. Dentro desta perspectiva o Quadro Europeu Comum de Referência, que oficializa a AA, criado pelo Conselho da Europa, tem por objetivo específico "servir de base para a elaboração dos programas de aprendizagem das línguas e organizar suas certificações e, pôr em prática um aprendizado auto dirigido ${ }^{19 "}$ (2001:12).

A Perspectiva Acional, segundo Puren (2006), visita a metodologia ativa, para resgatar o "agir coletivo do aprendiz", e o agir social ou o fazer social. O fazer coletivo já não é mais tão importante. A ideia maior agora é de formar o aprendiz como "ator social", participante e integrado num grupo. Obviamente, formando um indivíduo/ator social realizador de ações individuais no interior de situações comunicativas particulares, em circunstâncias e meios também particulares. Tratamos aqui da questão da ação do aprendiz dentro de sua formação linguística, atingindo todos os conceitos e aspectos ligados ao ensino-aprendizagem, mas voltada para a necessidade imediata do aluno e trazida para sua realidade. Dessa forma, a Abordagem Acional representa mais do que uma perspectiva para o ensino da língua francesa; representa uma tendência do comportamento do homem atual, que busca acessar informações, adquirir conhecimentos e realizar ações num tempo cada vez menor.

As metodologias e abordagens apresentadas acima objetivaram, através de suas propostas, um ensino/aprendizagem do francês que fosse eficaz e que apresentasse bons resultados. As modalidades de ensino, que nelas estão inscritas, procuraram responder às necessidades de um público, que por sua vez, tentou adequar-se a um mundo cada vez mais globalizado. Veremos, a seguir, as modalidades que antecederam o Francês para fins específicos e suas propostas para o ensino da língua francesa estrangeira, todas, com origem na Metodologia Direta e válidas até hoje.

\section{Francês para fins Específicos (FOS)}

A partir dos anos 60, um novo público, solicitante de uma comunicação profissional, levou muitos especialistas a considerar que aprender uma língua era responder a um objetivo "funcional". A língua, nesta perspectiva, era vista como um

\footnotetext{
${ }^{19}$ Texto original em francês : «(...) élaborer des programmes d'apprentissage des langues (...) organiser une certification en langues (...) mettre en place un apprentissage autodirigé (...) (CADRE EUROPÉEN COMMUN / CONSEIL D 'EUROPE : 2001, 12). Nossa tradução.
} 
instrumento a ser utilizado em um momento e em um lugar precisos. A França, nesse mesmo período, percebeu que para manter o estatuto internacional de sua língua, precisava considerar como partes integrantes de sua cultura a ciência e a tecnologia. Diante desta realidade, o país decidiu priorizar as línguas científicas e técnicas de várias profissões (medicina, direito, turismo, hotelaria, secretariado, etc.), deixadas de lado, até então, em seus investimentos linguísticos.

O ensino de uma língua para fins específicos foi estabelecido há trinta anos, com objetivos comerciais e profissionais. Puren mostra em sua obra - Histoire des Méthodologies de l'enseignement des Langues (1988) - que o caminho percorrido pelas metodologias de ensino foi uma consequência da necessidade que o homem teve de comunicar-se melhor e de forma mais eficaz para estabelecer novos contatos, novos acordos, descobrir outras culturas, etc. O Francês para fins Específicos originou-se do resultado dos grandes ajustes metodológicos do FLE: o desafio de inserir o aprendiz cada vez mais no processo de ensino/aprendizagem do francês, fazendo-o agir e realizar suas próprias ações, atendendo às suas próprias necessidades.

O FOS é uma modalidade de ensino/aprendizagem do francês que tem por objetivo responder a uma necessidade específica de um público específico. Para que um programa de ensino de francês pertença a esta modalidade, é preciso que seus objetivos sejam precisos e construídos exclusivamente a partir das necessidades de seu solicitante/aprendiz, além de ter um tempo limite para atingir o objetivo estabelecido na demanda, características que outras modalidades de ensino do francês, língua estrangeira, não possuem.

O Dicionário de Didática do Francês de Cuq (2004) nos ajuda a melhor explicálo, dizendo que o FOS nasceu "da preocupação em adaptar o ensino do FLE para públicos adultos, desejosos em adquirir ou aperfeiçoar suas competências em francês para uma atividade profissional ou acadêmica." Segundo ainda o mesmo dicionário, "o FOS inscreve-se num procedimento funcional de ensino: o objetivo da formação linguística não é o domínio da língua em si, mas o acesso aos conhecimentos linguageiros em situações identificadas de comunicações profissionais e acadêmicas" (CUQ, 2004: 109) ${ }^{20}$.

\footnotetext{
${ }^{20}$ Texto original em francês - (CUQ, $\left.2004: 109\right)$ - «du souci d'adapter l'enseignement du FLE à des publics adultes souhaitant acquérir ou perfectionner des compétences en français pour une activité professionnelle ou des études supérieures » - «le FOS s'inscrit dans une démarche fonctionnelle d'enseignement et tissage: l'objectif de la formation linguistique n'est pas la maîtrise de la langue en soi mais l'accès à des
} 
Français sur Objectif Spécifique, como terminologia didática, apareceu no final dos anos 80 e não representa uma nova proposta de ensino, pois podemos encontrar algumas de suas marcas em outros discursos. Quando falamos de marcas em outros discursos, falamos da noção de FOS, construída nos últimos trinta anos, através de outras terminologias (Français Scientifique et Tecnhique, Français Fonctionnel, Langue de Spécialité, Langue Spécialisée ou Français de Spécialité e Français Instrumental) que corresponderam às propostas pedagógicas que buscaram responder às demandas específicas de suas respectivas épocas; cada uma com sua especificidade de ensino.

Para compreendermos melhor como o FOS foi definido nos últimos anos, passaremos às outras propostas de ensino/aprendizagem que o antecederam. Algumas terminologias perderam-se no tempo e não são mais empregadas, outras ainda existem e estão mais bem definidas enquanto proposta de ensino do francês língua estrangeira.

A terminologia mais antiga é a do "Français Scientifique et Technique" (FST). As duas palavras associadas, científico e técnico, resultaram de uma decisão política no final dos anos 50, que tinha por objetivo a defesa dos interesses econômicos da França e de sua influência geopolítica, particularmente em países em desenvolvimento econômico, nos quais a língua inglesa se fazia muito presente.

Apoiado pelo governo francês, o $F S T$ foi a primeira modalidade de ensino reconhecida e muitas pesquisas referentes ao ensino/aprendizagem do francês língua estrangeira apareceram como consequência (CUQ e GRUCA: 2005). No início, o FST dedicou-se às terminologias e à descrição de vocabulários especializados, já que se tratava de domínios científicos. Algumas obras foram publicadas na época, como por exemplo, "Vocabulaire général d'orientation scientifique" (1971), elaborado pelo Crédif, que apresentava listas de palavras comuns a muitas ciências e era usada para ensinar as expressões científicas às pessoas que desejavam estudar ou estagiar na França, como bem nos lembra Holtzer (2004). Outra obra importante na época, também citada por esta autora, o "Français Scientifique et Technique" (Hatier, 1971), um dos primeiros métodos de ensino do francês específico, apresentava um ensino feito através de metodologias estruturalistas, muito mais centradas em conteúdos do que em ensinos funcionais, levando em conta fatores situacionais e comunicativos. Os trabalhos feitos com as listas de vocabulários foram abandonados aos poucos, pois havia uma

savoir-faire langagiers dans des situations dûment identifiées de communication professionnelles ou académiques ». Nossa tradução. 
necessidade maior de se estudarem os textos científicos e seus discursos, bem como o funcionamento das diferentes comunicações especializadas, mudanças essas influenciada pela interação discursiva e pela análise conversacional.

«Os primeiros estudos desenvolvidos sobre o discurso especializado e sobre os discursos científicos vão aparecer no final dos anos $70^{21} »$, com Darot e Beacco (HOLTZER:2004, 16), separando as duas expressões: científico e técnico. O discurso científico fora descrito como um conjunto de diferentes discursos e classificado em dois tipos: o da interlocução interna (as trocas discursivas entre especialistas) e o da interlocução externa, referente às difusões das informações, todos os dois definidos do ponto de vista comunicativo.

Este novo caminho tomado, a partir dos discursos especializados ou sobre temas de especialidade, que se referia aos especialistas da área em questão ou interessados no tema, vai receber novo conceito terminológico. O reconhecimento dos diferentes gêneros existentes nas áreas científicas e técnicas conduziram a uma maior especificação dos objetivos propostos pelo FST.

Estas mudanças de foco de trabalho levaram muitos estudiosos a se perguntar sobre a melhor maneira de tratar a informação científica de forma que ela fosse viável para a divulgação e intelectualmente acessível a um público diverso, de especialistas a não especialistas. Assim, a discussão sobre os discursos em produções orais e escritas fez com que esta modalidade fosse aplicada somente em nível superior. O público do Francês Científico e Técnico era composto de adultos, já com uma formação científica e técnica em língua materna, portanto, conhecedores de sua especialidade. Nesse contexto, cabe citar a coleção Français Fonctionnel - Guia Pedagógico elaborado por Annie Monnerie do Ciep em 1980, com a participação de José Peguero, Editora CLE International.

Esta coleção propunha temas voltados ao comércio, à economia e às ciências exatas. Cada seção temática era composta de sete cadernos, todos eles acompanhados de um Guia Pedagógico e um manual para o aluno. Assim como nos manuais da Abordagem Comunicativa de FLE, esse livret méthodologique detalha todas as atividades em etapas para o professor com as informações extras necessárias para a sua ação em sala de aula. O manual do aluno, apesar da coleção chamar-se Français

\footnotetext{
${ }^{21}$ Texto original em francês: «(...) Les premières études sur les discours spécialisés et sur les spécificités du discours scientifique paraissent à la fin des années 1970 (...) »(HOLTZER : 2004, 16). Nossa tradução.
} 
Fonctionnel, revela-nos um trabalho em francês científico e técnico explícito, com atividades e explicações da língua francesa voltadas exclusivamente para o tema específico.

O FST como ensino, através da política linguística desenvolvida pela França, diversificou-se rapidamente, tornando a sua terminologia didática muito limitada diante das várias áreas específicas, possíveis de atuação. Nos anos 90, novos acordos de cooperação linguística foram firmados, criando novas disciplinas de estudos - o francês do comércio, o administrativo, o do turismo, etc. $\mathrm{O}$ aparecimento destas novas disciplinas, com numerosas publicações voltadas para o ensino do francês especializado, fez com que uma nova terminologia aparecesse: o "Français de Spécialitê"(FS).

Essa foi a primeira expressão utilizada para nomear os métodos voltados para os públicos específicos e estudantes de francês numa perspectiva profissional ou universitária. Conforme estudo feito do "Etat de la francophonie dans le monde" ${ }^{22}$,de 1997, esses métodos concentravam todo o seu trabalho nos discursos que serviam de base às formações linguísticas, correspondendo às necessidades profissionais de cada setor; como por exemplo, o 'francês da medicina', 'o francês da psicologia', 'o francês jurídico', ou ainda, em áreas de atividades profissionais, como o 'turismo', a 'hotelaria' e o 'banco'.

Français de Spécialité, Langue Spécialisée, Langue de Spécialité, ou ainda Langue Professionnelle, denominação apresentada atualmente por Mourlhon-Dallies (2008). Essas expressões procuraram delimitar seu campo de atuação dentro do ensino da língua francesa, como resposta a uma necessidade detectada em suas respectivas épocas. Essa noção reagrupa três categorias: as línguas científicas, as técnicas e as profissionais, classificando-as em dois subgrupos: as línguas científicas e as técnicas.

Nos anos 90, a situação do FS dá um grande salto com um novo investimento do governo francês. Com o interesse do governo em estabelecer novos contatos internacionais e oferecer formações linguísticas para futuros funcionários europeus com intuito da integração na Comunidade Européia, a produção editorial respondeu à altura, publicando suas coleções, manuais para as profissões mais em voga na época. As fronteiras entre as especialidades, contudo, ainda não estavam bem definidas, deixandose misturar em propostas generalizadas. Alguns estudiosos responderam a esta problemática, afirmando que cada especialidade tinha sua própria língua, tendência que

\footnotetext{
${ }^{22}$ Haut Conseil de la Francophonie (1997): État de la Francophonie dans le monde, données 1995-1996 et cinq études thématiques, Paris, la Documentation française, 631 p. (citado em HOLTZER : 2004, 18)
} 
ficou cada vez mais forte. Alguns autores defendiam a língua especializada, definindo-a como o uso de uma língua natural de um meio específico que permitiria a compreensão do tema específico. A língua tem um caráter unitário e é o seu uso que a torna uma língua de especialidade.

O FOS entra em cena, como já foi dito anteriormente, e chega com uma noção que não é nova, mas com uma terminologia que deixa claro qual é a sua área de atuação. O termo FOS, Français sur Objetifs Spécifiques, vai concentrar-se em temas específicos trabalhados a partir de uma demanda e de necessidades do aluno, com o objetivo único de satisfazê-los.

Em paralelo, um ensino do francês com finalidade também específica, como forma de aprendizagem, era desenvolvido na América Latina, nos anos 70, com o nome de Francês Instrumental ${ }^{23}$. Esta modalidade de ensino visava o público de estudantes que precisavam desenvolver uma competência em leitura de textos especializados. Ao mesmo tempo, na França, algumas instituições científicas vinham criando cursos de francês com programas específicos para atender um público estrangeiro em função da sua própria demanda. Atualmente, essas modalidades, o Francês Instrumental e o Francês para fins específicos, possuem caminhos e abordagens distintas.

Para entendermos o lugar do FOS no Ensino do Francês para fins Específicos, é interessante conhecermos duas situações de ensino que são bem opostas: a primeira é o ensino de língua em escolas, com um público mais amplo. Os alunos aprendem o francês, durante alguns anos, em algumas horas por semana. Esta forma de ensino é caracterizada de 'Francês Geral', pois trata-se de um ensino extensivo, tendo como objetivo fundamental a formação acadêmica pessoal, como em matemática, por exemplo.

A outra forma é proveniente de uma demanda específica, de um meio profissional ou acadêmico. Para esta segunda situação, a formação terá por objetivo melhorar ou aperfeiçoar rapidamente as competências linguísticas dos estudantes que devem se integrar em situações profissionais ou acadêmicas. Um bom exemplo, dado por Parpette e Mangiante (2004), é aquele que o governo francês teve que contratar enfermeiras espanholas para compensar a sua falta de pessoal nos serviços dos hospitais

\footnotetext{
${ }^{23}$ Com o distanciamento histórico, é possível considerar as origens do FOS, no início da década de 80, como vanguarda da abordagem comunicativa, compreendendo o aluno como alguém que deveria estar apto a interagir em diferentes situações de comunicações do dia-a-dia, o que implica ouvir, falar, ler e escrever. Já o Francês Instrumental, que até hoje é ensinado em universidades, é voltado para a leitura de textos. (JOVER-FALEIROS: 2006, 6)
} 
franceses. Essas enfermeiras tiveram uma formação para melhorar sua competência linguística antes de serem admitidas nos locais de trabalho. Dessa forma, o FOS caracteriza-se por ser uma abordagem que responde a uma demanda precisa, baseandose num conteúdo dentro de um tempo estritamente delimitados. Os objetivos visados são tratados caso a caso, elaborando-se programas, adaptados a cada demanda, às vezes, urgente como o caso das enfermeiras espanholas, ou num período de tempo mais estendido, como o caso dos alunos de engenharia, candidatos ao duplo-diploma com a França pela Escola Politécnica da Universidade de São Paulo (EPUSP).

Atualmente, a noção de ensino para fins específicos está mais bem definida, contudo, vemos ainda que «FOS (Français sur Objectif(s) Spécifique(s)) ${ }^{24} » \mathrm{e}$ «Français de Spécialité» são dois termos que, por um lado, se complementam e, por outro, diferenciam-se, misturam-se e confundem-se em suas atuações. Como já visto anteriormente, a expressão «Français de Spécialité » foi a primeira a ser utilizada para designar os métodos centrados em públicos específicos em perspectivas profissionais e universitárias. O que diferencia estas duas terminologias como propostas de ensino é a demanda. Vemos que, em FOS, a demanda de uma formação linguística precisa ser concreta, para um público específico, com necessidades e objetivos igualmente específicos e em um tempo preciso, ao contrário do Français de Spécialité que é uma abordagem mais global de uma disciplina ou de um ramo profissional, aberta ao público mais geral possível (MANGIANTE e PARPETTE; 2004:17) ${ }^{25}$.

A necessidade de distinguir bem a noção de $F O S$ de outras terminologias didáticas é fundamental para o ensino/aprendizagem da própria língua francesa. Expressões como FOS, francês para fins específicos, correm o risco de serem banalizadas facilmente, fazendo com que sejam julgadas transparentes e aplicadas conforme um entendimento direto, sem um real questionamento sobre a proposta.

\section{Princípios básicos}

Para que possamos delimitar uma proposta e defini-la como FOS, é preciso levar em conta alguns aspectos fundamentais que nos permitem "exercê-lo" com propriedade.

\footnotetext{
${ }^{24}$ Le pluriel est devenu par conséquent de plus en plus légitime. Autrement dit, écrire FOS au pluriel, revient à témoigner de l'enrichissement progressif $d u$ champ de l'enseignement du français professionnelles, par strates de préoccupations successives. Ces préoccupations concernent le lexique, la grammaire, le discours, soit, au plan de l'histoire des méthodologies, la grande majorité des «entrées» qui ont, au fil des ans, structuré l'enseignement des langues vivantes en France. (MOURLHONDALLIES, F. Enseigner une langue à des fins professionnelles. Paris, Didier, 2008).

${ }^{25}$ Texto original em francês - (MANGIANTE e PARPETTE, $2004: 17$ ) - « ...est une approche globale d'une discipline ou d'une branche professionnelle, ouverte à un public le plus large possible ».
} 
Jean-Marc Mangiante e Chantal Parpette apresentam em seu livro Le Français sur Objectif Spécifique: de l'analyse de besoins à l'élaboration d'un cours, 5 etapas que permitem identificar uma proposta para fins específicos e organizá-la a fim de construir um programa de ensino. As etapas de um curso FOS, segundo Mangiante e Parpette são as seguintes: a demanda, a análise de necessidades, a coleta de dados, a análise de dados e, por fim, a elaboração do programa e do material didático.

Conforme os autores citados acima, para que se tenha um curso FOS, é preciso que haja uma demanda clara e objetiva de formação linguística em Francês, língua estrangeira, com um objetivo específico. Esta demanda pode vir dos próprios indivíduos com os quais se vai desenvolver o trabalho, ou pode vir de uma instituição privada ou pública. O importante é que se tenha uma solicitação formal, pois é ela que nos dará as informações básicas para que o curso aconteça: o público com o qual vamos trabalhar as competências linguísticas a serem adquiridas, a duração da formação e seu custo. Quanto ao tempo, quanto menor o tempo para a formação, mais preciso é o trabalho a ser desenvolvido. Se tivermos mais tempo de trabalho, podemos nos dedicar mais à formação e, dependendo dos objetivos, optar por alguns materiais existentes no mercado.

E quando não temos uma demanda, e sim uma oferta? Nesta situação, o caminho não é muito diferente, precisamos de qualquer forma identificar o público, a especialidade, os objetivos a serem atingidos e o tempo de disponibilidade para o trabalho. Dependendo das respostas, estaremos em FOS ou em FS.

Com a solicitação feita, passamos à segunda etapa que é a análise de necessidades, etapa que nos permite verificar a dimensão real do pedido e estabelecer os primeiros objetivos do curso. As necessidades projetivas serão determinadas pelo professor a partir do que foi exposto pelo solicitante e estas serão estabelecidas em torno das competências reais a serem adquiridas e das reais situações de comunicação.

Estas necessidades serão conhecidas mais precisamente na coleta de dados, pois é neste momento que o professor responsável pelo curso parte para a "exploração" da área. Cabe frisar que as necessidades pré-estabelecidas pelo professor não são garantidas e nem fixas, pois mudam conforme o curso evolui.

Uma outra questão referente às necessidades e que é importante ser discutida aqui, são as informações expostas pelos atores envolvidos na demanda. Muitas vezes, temos a instituição ou o aluno que solicita e apresenta as suas necessidades, conforme seu entendimento. Cabe, então, nesse momento, ao professor identificá-las e se este não 
estiver satisfeito, deverá recorrer a questionários e entrevistas com seu(s) aluno(s) para obter todas as informações que ele acreditar serem pertinentes ao programa de ensino. Por último, o mesmo professor deverá recorrer as suas experiências pessoais, se ele as tiver, em relação à área a ser trabalhada. Ele deverá juntar todas as informações e discernir o que lhe é válido como informação.

Depois de ter identificado e estabelecido estes objetivos, passamos à coleta de dados. Nesta etapa, fazemos uma exploração na área do futuro trabalho, através de entrevistas com pessoas que atuam na especialidade e do recolhimento de documentos autênticos, que dizem respeito à especialidade em questão. Esta fase do trabalho, que é todo o reconhecimento da área específica e das pessoas com quem vamos trabalhar, é extremamente importante. Temos que lembrar que o professor não é um especialista na área, então, quanto mais informações sobre o assunto ele puder obter, mais preparado estará para elaborar seu programa e desenvolver o seu material didático.

A elaboração didática é a última etapa e consiste na concepção do programa, no desenvolvimento do material didático, na escolha da estratégia de trabalho a ser utilizada pelo professor, todo esse conjunto tendo por objetivo assegurar o cumprimento do programa. O professor de FOS deve ter em mente que a sua participação é fundamental para o aluno, fazendo com que ele trabalhe. O momento da aula deve ser reservado para o aluno agir, com o intuito de favorecer uma comunicação real, com troca de informações. O trabalho em FOS, se possível, deve procurar combinar o trabalho coletivo, desenvolvido em sala, com o trabalho individual de cada aluno. Com este tipo de atitude, o professor pode favorecer o seu próprio trabalho, em relação ao programa estabelecido, e favorecerá o trabalho que será desenvolvido pelo aluno, tornando-o autônomo, mais participativo e engajado com a proposta.

É nesta fase também que verificaremos as hipóteses que foram formuladas nas etapas anteriores. Podemos dizer que nas etapas da demanda e da análise de necessidades formulamos as primeiras hipóteses. Com a coleta de dados, temos condição de ajustar algumas das hipóteses formuladas anteriormente e, por fim, na análise de dados e na elaboração didática é que se fará o tratamento das informações recolhidas e a confirmação das hipóteses que foram levantadas no início. Com todas as informações à sua disposição, o professor poderá estabelecer uma estratégia de trabalho, elaborar um programa e material didático.

Em uma situação de ensino para fins específicos, o professor assume o papel de criador/construtor do curso. Ele se confronta a uma realidade que não é a sua e deverá 
buscar através de suas próprias pesquisas respostas para suas inquietações. Esse professor torna-se dinâmico e versátil, pronto para se adaptar a novas situações, não aceitando mais atividades prontas sem antes se questionar sobre a sua eficácia. No FOS, o professor tem a oportunidade de transpor seus conhecimentos adquiridos e buscar outros, teóricos e/ou empíricos, que o auxiliem na sua atuação profissional e na atuação de seus alunos.

\section{Conclusão}

Conhecer o caminho das metodologias de ensino/aprendizagem do francês, língua estrangeira, faz com que entendamos os movimentos questionadores das teorias que permearam e permeiam todas essas propostas de ensino com as quais o professor trabalha na sua prática. Cada vez mais, o próprio mercado que cerceia o ensino de línguas estrangeiras, traz-nos publicações atualizadas de métodos de ensino praticamente prontos, o que provoca certa acomodação por parte do professor. $\mathrm{O}$ conhecimento de teorias desenvolvidas e discutidas por diferentes linhas de pesquisas permite que o professor tenha uma visão analítica e crítica de sua própria atuação, fazendo-o entender melhor os processos de ensino/aprendizagem de forma a beneficiar o seu aluno e, sobretudo também, uma visão crítica do que lhe é proposto como ideias e instrumentos para seu trabalho.

\section{Referências}

ALMEIDA FILHO, J. C. P. Dimensões comunicativas no ensino de línguas. $5^{\circ}$ Edição, Campinas, SP: Pontes Editores, 2008.

ALVAREZ, G. et AUPECLE, M. Français Instrumental et Français Fonctionnel. Deuxième rencontre mondiale des Départements d'Études Françaises - Comité latinoaméricain de l'AUPELF, Strasbourg, 17 - 23 Juillet, 1977.

BEZERRIL CARDOSO, A. Les Serments de Strasbourg: importância histórica e filológica na consolidação do francês. Dissertação de Mestrado / UFPB. Ano de obtenção: 2007.

CADRE EUROPÉEN COMMUN DE RÉFÉRENCE POUR LES LANGUES. Strasbourg, Conseil de l'Europe : Didier, 2001. 
CARRAS, C., TOLAS, J., KOHLER, P. et SZILAGYI, E.. Le Français sur Objectifs Spécifiques et la classe de langue. Paris: CLE International, 2007.

CHEVALIER, J.-C. Français de l'avenir et avenir du français. in DEMARTYWARZÉE, J. e ROUSSEAU, J. Français de l'avenir et avenir du français - Cahier du Ciep. Didier, Paris, 2000.

COURTILLON, J. Élaborer un cours de FLE. Hachette, Paris, 2003.

COSTE, D. Le renouvellement méthodologique dans l'enseignement du français, langue étrangère. (Français dans le monde, $\mathrm{n}^{\circ}$ 87, 1972), in La pédagogie du français langue étrangère - Orientations théoriques - Pratiques dans la classe. Paris, Hachette, 1978.

CUQ, J.-P. Dictionnaire de Didactique du Français - Langue étrangère et seconde. Paris, CLE International, 2003.

CUQ, J.-P. et GRUCA, I, Cours de didactique du français langue étrangère et seconde. Grenoble : PUG, 2005.

DEMARTY-WARZÉE, J. e ROUSSEAU, J. Français de l'avenir et avenir du français - Cahier du Ciep. Didier, Paris, 2000.

DELSOL, A. e DUCHAIGNE, R. Le Français Scientifique et Technique (Volume 1 e 2), Paris, Ministère des Affaires Étrangères e Editora Didier, 1971.

EMMERICK DE ALMEIDA, A. Por uma perspectiva intercultural no ensinoaprendizagem de Francês Língua Estrangeira. Tese de Doutorado / FFLCH-USP. Ano de obtenção: 2008.

GALISSON, R. E COSTE, D. (Dir.), Dictionnaire de didactique des langues, Paris, Hachette, 1976.

GAONAC'H, D. - Théories d'apprentissage et acquisition d'une langue étrangère, Paris: Hatier-Crédif, 1987.

Acquisition et utilisation d'une langue étrangère. L'approche cognitive. Paris: Hachette, 1990.

GERMAIN, C. Évolution de l'enseignement des langues : 5000 ans d'histoire. Paris, CLE International, 1993.

HOLTZER, G. Du français fonctionnel au français sur objectifs spécifiques - Histoire des notions et des pratiques. In Le Français dans le monde, janvier 2004, CLE International / FIPF. 
KLINKENBERG, J.-M. LES Politiques linguistiques: Pour qui? Pour quoi?, in DEMARTY-WARZÉE, J. e ROUSSEAU, J. Français de l'avenir et avenir du français - Cahier du Ciep. Didier, Paris, 2000.

LEHMANN, D. Objectifs spécifiques en langue étrangère - Les programmes en question, Paris: Hachette, 1993.

MANGIANTE, J.-M e PARPETTE, C. Le Français sur Objectif Spécifique: de l'analyse des besoins à l'élaboration d'u cours. Paris: Hachette, 2004.

MONNERIE, A. e PEGUERO, J. Livret Méthodologique, Paris, CLE International, 1980.

Algèbre linéaire. Paris, CLE International, 1980.

MOURLHON-DALLIES, F. Enseigner une langue à des fins professionnelles. Paris, Didier, 2008.

PIETRARÓIA, C. - Percursos de leitura, São Paulo, Annablume, 1997. - Questões de leitura, São Paulo, Annablume, 2001.

PUREN, C. Histoire des Méthodologies de l'enseignement des langues. Paris, CLE International, 1988.

Formes pratiques de combinaison entre perspective actionnelle et approche communicative : analyse comparative de trois manuels. Publicado em 05 de janeiro de 2008, na página internet da Association des Professeurs de langues vivantes http://www.aplv-languesmodernes.org.

Explication de textes et perspectives:la littérature entre le dire scolaire et le faire social. Publicado em 08 de outubro de 2006, na página internet da Association des Professeurs de langues vivantes - http://www.aplv-languesmodernes.org.

Les implications de la perspective de l'agir social sur la gestion dês connaissances em classe de langue-culture: da la compétence à la compétence informationnelle. Publicado em 11 de fevereiro 2009, na página internet da Association des Professeurs de langues vivantes - http://www.aplv-languesmodernes.org.

SIGNORINI, I., Língua(gem) e Identidade - elementos para uma discussão no campo da aplicação. Campinas: Mercado das Letras, 2002.

SOUCHON, M. Analyse des verbalisations produites par des apprenants suite $\grave{a}$ une activité de lecture en français langue étrangère. In: Appropriation des Langues au Centre de la Recherche / Spracherwerb als Forschngsgegenstand, coordenado por KÜPERS, H. e SOUCHON, M. Frankfurt: Peter Lang, 2002.

TAGLIANTE, G. La classe de langue. Paris, CLE International, 2006. 
TRUCHOT, C. L'Espace externe du français en Europe, in DEMARTY-WARZÉE, J. e ROUSSEAU, J. Français de l'avenir et avenir du français - Cahier du Ciep. Didier, Paris, 